Article

\title{
Modelling Crack Propagation in Aluminium-Alloys 2524-T3 and 7050-T7452 Subjected to Fatigue Loading at Low Temperature
}

\section{D. Liu and J. J. Xiong *}

School of Transportation Science and Engineering, Beihang University, Beijing 100191, China; mdliu@buaa.edu.cn

* Correspondence: jjxiong@buaa.edu.cn

Abstract: This paper seeks to model the crack propagation in of AAs (aluminum-alloys) 2524-T3 and 7050-T7452 subjected to fatigue loading at low temperature. Fatigue crack growth tests were performed on AAs 2524-T3 and 7050-T7452 subjected to constant-amplitude and actual random-spectra loading histories at room temperature of about $25{ }^{\circ} \mathrm{C}$ and at cryogenic temperature of $-70{ }^{\circ} \mathrm{C}$, respectively, to determine their crack growth properties and residual lives. The interaction mechanisms between cryogenic temperature and the fatigue load were deduced on the basis of the results of fractographic analysis. Temperature-dependent residual lives under actual random-spectrum load history were modeled based on a modified accumulation damage rule by accounting for the load interaction. Good correlation was achieved between the predictions and actual experiments, demonstrating the practical and effective use of the proposed method.

Keywords: fatigue; crack growth; low temperature; residual life; aluminum-alloy

\section{Nomenclature}

$a$

crack size or length

$a_{0} \quad$ initial artificial prefabricated crack

$B \quad$ thickness of specimen

C crack propagation resistance coefficient 
da/dN crack growth per stress cycle

$f_{0} \quad$ crack opening function

K nominal stress intensity

$K_{C} \quad$ fracture toughness

$K_{\max } \quad$ maximum nominal stress intensity

$\left(K_{\max }\right)_{\text {eff }} \quad$ effective maximum nominal stress intensity

$\left(K_{\max }\right)_{t h} \quad$ maximum nominal stress fracture threshold

$\left(K_{\max }\right)_{O L} \quad$ overload maximum nominal stress intensity

$m \quad$ material constant

$m_{1} \quad$ material constant

$m_{2} \quad$ material constant

$m_{3} \quad$ material constant

$N \quad$ number of stress cycle

$r \quad$ overload shut-off ratio

$R \quad$ stress ratio

$R_{\text {eff }} \quad$ effective stress ratio

$W \quad$ width of specimen

$Z_{O L} \quad$ size of overload plastic zone

$\Delta a \quad$ increment of crack growth

$\Delta a^{\prime} \quad$ increment of crack growth through the overload zone

$\Delta K \quad$ stress intensity range

$\Delta K_{t h} \quad$ fracture threshold

$\Delta P \quad$ load range.

$\sigma_{b} \quad$ tensile ultimate strength 
AA aluminium alloy

\section{INTRODUCTION}

Because of their superior stiffness and strength, excellent resistance to creep, oxidation and corrosion, and good fracture toughness, advanced metallic alloys (e.g., titanium and aluminium alloys, Ni-based single-crystalline or polycrystalline superalloys, etc.) are widely used in advanced aircrafts and aero-engines as airframe component and gas turbine blade materials, where they are commonly encounter a wide range of temperature $\left(-5\right.$ to $\left.-60^{\circ} \mathrm{C}\right)$ at high flight altitudes ${ }^{[1-4]}$. Low temperatures can strongly affect the fatigue ductile-brittle transitionin mechanism ${ }^{[5-7]}$, fatigue resistance $^{[8]}$, fracture threshold ${ }^{[5]}$ and toughness ${ }^{[9]}$, and crack propagation rate ${ }^{[9-11]}$ of metallic materials, particularly, aluminum alloy. The reason for this is that fatigue damage at the crack tip is strongly affected by the hydrogen-embrittlement process $^{[12]}$, and low temperature generally retardates the hydrogen-embrittlement process to enhance fatigue resistance of some metallic materials ${ }^{[3-5]}$. A significant body of research exists covering new quantitative models for depicting fracture toughness $^{[6,7]}$ and threshold ${ }^{[5,13]}$, and crack growth laws ${ }^{[13,14]}$ at low temperature. In addition, based on the linear elastic fracture mechanics (LEFM), finite element (FE) modelling for crack propagation behavior and residual life at low temperature are also covered in several works ${ }^{[14,15]}$. As a result, fully understanding the effects of low temperatures on the fatigue properties and damage mechanism of metallic alloys at low temperatures is becoming increasingly important for assessing failure limits and reliability during the design prediction stage of advanced aircrafts and gas turbine engines.

During actual operation of aircrafts or steam turbine engines, many metallic alloy components often undergo variable-amplitude rather than constant-amplitude loading histories, and the effects of load interaction have an appreciable influence on fatigue lives in the environment of low temperature $^{[14,16]}$. Therefore, low temperature fatigue under variable amplitude loading histories is the single most common cause of failures of aircrafts or gas turbine engines. Although a large amount of re- 
search has been conducted on the fatigue properties and lives of alloy steels and superalloys at low temperatures, the effect of low temperature on the crack growth properties of AAs 2524-T3 and 7050-T7452 has been scarcely reported, and the load interaction on the residual lives of the aforementioned alloys subjected to variable amplitude loading histories at low temperature has not been systematically studied. Hence, a need exists for fully understanding the effect of low temperature on the crack growth properties of AAs 2524-T3 and 7050-T7452; furthermore, a technique for assessing the load interaction effect in engineering design for advanced aircraft or gas turbine engines is desirable, which is the focus of this paper.

\section{EXPERIMENTS}

\subsection{Experimental methodology}

Because of their superior mechanical properties, AAs 2524-T3 and 7050-T7451 have been widely used in advanced aircrafts and gas turbine engines as airframe or rotor spindle materials, where they commonly experience random-spectra loading histories in a low temperature environment. The random-spectra loading can cause crack initiation and propagation from small defects in airframes. In this work, our objective was to determine and understand the effect of low temperature on the crack growth properties and the load interaction on the temperature-dependent residual lives of AAs 2524-T3 and 7050-T7451.

All CCT (centre-cracked tension) specimens for fatigue tests were manufactured from AA 2524-T3 or AA 7050-T7451. The mechanical properties for AAs 2524-T3 and 7050-T7451 are listed in Table 1, and the geometry and dimensions of the specimens are shown in Fig. 1. All specimens have an initial artificial prefabricated crack size $a_{0}$ of $8 \mathrm{~mm}$ through linear cutting and polishing. All fatigue tests were conducted on a MTS-880-100kN servo-hydraulic machine under axial cyclic loadings with a sinusoidal waveform at a loading frequency of $10 \mathrm{~Hz}$ in room environment (shown in Fig. 2). During tests, a WZHD0850 long focal-length optical telemicroscope with a measurement accuracy within $0.01 \mathrm{~mm}$ was utilized to measure the crack sizes at a specific interval of cyclic loading 
until the rupture of specimen. In addition, a SDGDYD-180/+350 environmental chamber whose temperature fluctuated within $\pm 2{ }^{\circ} \mathrm{C}$ was employed to maintain the testing temperatures of $-70^{\circ} \mathrm{C}$ cryogenic temperature through controlling the gas flow of gasified nitrogen from the YDZ-50 cryogenic liquid nitrogen cylinder. A pre-crack of about $2.0 \mathrm{~mm}$ length was made along both left and right notch-edge cracks on all specimens at the beginning of tests.

Four categories of crack growth tests were prepared. Two of them were constant-amplitude loading tests at room temperature of about $25^{\circ} \mathrm{C}$ and at cryogenic temperature of $-70^{\circ} \mathrm{C}$, to determine pure and low temperature crack growth properties, separately. Two other categories were actual random-spectra loading tests at about $25^{\circ} \mathrm{C}$ and at $-70^{\circ} \mathrm{C}$, to obtain pure and low temperature residual lives, respectively. The cryogenic temperature of $-70^{\circ} \mathrm{C}$ represent the lowest operation temperature to which AAs 2524-T3 and 7050-T7451 are commonly subjected in airframe applications. Furthermore, three stress ratios of $0.06,0.3$ and 0.5 were implemented for the tests of constant-amplitude loading, and at least three specimens were utilized for each stress ratio. Meanwhile, four reference stress levels of $68 \mathrm{MPa}, 75 \mathrm{MPa}, 91 \mathrm{MPa}$ and $109 \mathrm{MPa}$ were employed for the tests of actual random-spectra loading on AAs 2524-T3 and 7050-T7451, separately, and at least three specimens were used for each reference stress level.

Fig. 3 shows the sequences and the coefficient values of 116884 load peaks and valleys (i.e., 58442 load cycles) in a block of actual random-spectra loading history for AAs 2524-T3 and 7050-T7451. Notably, actual values of 116884 load peaks and valleys are determined by multiplying the reference stress level by the load coefficients in Fig. 3. As a result, four actual random-spectra loading histories for AAs 2524-T3 and 7050-T7451 can be obtained by multiplying the reference stress levels of $68 \mathrm{MPa}, 75 \mathrm{MPa}, 91 \mathrm{MPa}$ and $109 \mathrm{MPa}$ by the load coefficients in Fig. 3.

\subsection{Experimental results and dicussion}

Through constant-amplitude loading tests, the experimental dataset of crack length $a_{i}$ versus number of stress cycles $N_{i}$ were determined and the crack growth rates $(d a / d N)_{i}$ corresponding to the crack length $a_{i}$ were calculated based on the secant method ${ }^{[17]}$ from an experimental dataset 
$\left[a_{i}, N_{i}\right]$. In accordance with standards ASTM E647-11 ${ }^{[17]}$, the stress intensity range for the CCT specimen is

$$
\Delta K=\frac{\Delta P}{B} \sqrt{\frac{\pi \alpha}{2 W} \sec \frac{\pi \alpha}{2}}
$$

where $\alpha=2 a / W, W$ is the width of specimen, $B$ is the thickness of specimen and $\Delta P$ is the load range.

By means of Equation (1), the stress intensity range $(\Delta K)_{i}$ corresponding to the crack length $a_{i}$ were also calculated and an experimental dataset $\left[(d a / d N)_{i},(\Delta K)_{i}\right]$ was then obtained. The experimental datasets under constant-amplitude loading at about $25^{\circ} \mathrm{C}$ and $-70{ }^{\circ} \mathrm{C}$ are shown in Fig. 4 . The results in Fig. 4 lead to the following deductions: (i) The crack growth rates for both alloys in both temperature environments increase with the increasing stress ratio. (ii) In the same stress ratio case, the crack growth rates for both AAs are less at $-70^{\circ} \mathrm{C}$ than at $25^{\circ} \mathrm{C}$. Hereby, we propose that low temperature substantially and beneficially affects the crack growth behaviour of AAs 2524-T3 and 7050-T7451. (iii) In the case of the same stress ratio, the difference in fatigue crack growth rate between both temperature environments decreases with the increasing stress intensity, this means that the effect of low temperature weakens with the increasing stress intensity.

The experimental results under actual random-spectra loading are shown in Table 2. The results in Table 2 results in the following deductions: At the same reference stress level, the mean values of residual life are greater at $-70^{\circ} \mathrm{C}$ cryogenic temperature than at $25^{\circ} \mathrm{C}$ room temperature. In addition, the differences of residual lives between both temperature environments decrease with the increasing reference stress level. We therefore conclude that low temperature has a notable and beneficial effect on the residual life of AAs 2524-T3 and 7050-T7451.

\subsection{Fractographic analysis}

In general, fracture surfaces exist valuable information sources of trace evidence (e.g., hachures or fatigue lines, etc.) to indicate the origin or origins of crack, dominant crack growth path, residue, fracture mode, etc. Thereby, by analyzing the characteristics on fracture surface, fractography is 
widely applied to identify the failure mode, to understand the nature of fatigue failure and the causes of crack initiation and growth, and to develop or verify theoretical failure predictions with real life failures. Scanning electron microscope (SEM) is generally used in fractographic analysis to determine the failures modes and to qualitatively reveal the likely natures of crack initiation and growth. To understand the failure mode and the natures of crack growth under load-environment interaction and load interaction, representative fracture surfaces of failed specimens were analyzed fractographically using a SEM to provide direct evidence of crack growth in regions not observable during the fatigue process. The fracture surfaces of both alloys are shown in Figs. 5 to 7. Significant results that emerged from the fractographic analysis are summarized as follows:

(i) Figs. 5 and 6 clearly show serial and fine plastic fatigue striations to demonstrate a smooth and stable crack growth under constant-amplitude loading, while Fig. 7 exhibits sparse and discrete plastic fatigue striations and abundant ductile dimples between fatigue striations to illustrate a significent load-interaction effect arising from the random-spectra loading, in other words, the load variations within actual random-spectra load history contribute to the alternation between a smooth and stable crack growth and an instantaneous sharp separation of the dimple at crack tip. The clear plastic fatigue striations appear on fracture surfaces of both alloys to indicate the occurrence of local plastic deformation at crack tip at room and low temperatures.

(ii) Figs. 5b, 6b, $7 \mathrm{~b}$ and $7 \mathrm{~d}$ clearly reveal the ductile transgranulars nature on fracture surfaces at $-70^{\circ} \mathrm{C}$ to decrease crack growth rate, ultimately increasing fatigue life. Meanwhile, Figs. $6 \mathrm{a}$ and $6 \mathrm{~b}$ evidently display the embrittlement feature on fracture surfaces of AA 7050-T7451 in both temperature environments. This observation implies that AA 7050-T7451 is more brittle than AA 2524-T3.

(iii) Figs. 5a, 6a, 7a and 7c demonstrate the greater crack growth zones consisting of fatigue lines and dimples on fracture surfaces under random-spectra loading than under constant-amplitude loading. This observation implicates that instantaneous large load variations within actual random-spectra loading history enhance the sharply tensile effect to accelerate crack growth. 
(iv) Figs. $7 \mathrm{a}$ and $7 \mathrm{~b}$ show no dimple on fracture surfaces under random-spectra loading at reference stress level of $91 \mathrm{MPa}$, while Figs. 7c and 7d demonstrate substantial dimples on those at $109 \mathrm{MPa}$. Moreover, Figs. $7 \mathrm{~b}$ and $7 \mathrm{~d}$ also involve the ductile transgranulars nature on fatigue surfaces under random-spectra loading, specilly, more significant ductile transgranulars nature can be observed at reference stress level of $91 \mathrm{MPa}$ than at $109 \mathrm{MPa}$. As a consequence, we propose that with the increasing reference stress level of random-spectra loading, the load interaction effect enhances, the load-environment interaction weakens, and the difference in residual lives between both temperature environments decreases.

Note that the above qualitative results of fractographic analysis provide an insight into fatigue damage development in metallic alloys under load-environment interaction and load interaction and constitute a fundamental basis for the development of a microstructural theoretical model for depicting the load-environment interaction. In order to develop microstructural theoretical model for depicting the load-environment interaction, the further works necessitate to quantitatively determine microstructural sizes of material (including grains and grain slip boundary, dimple, short crack, etc.) in the case of known loading and environment patterns. After this, it is possible to establish the theoretical relationship model between the microstructural sizes of material and loading and environment to quantitatively evaluate the load-environment interaction.

\section{MODELLING CRACK GROWTH BEHAVIOUR AND RESIDUAL LIFE}

\subsection{Depicting temperature-dependent crack growth behavior}

A three-parameter empirical power function formula is commonly used to characterize materials' crack growth properties as.

$$
\frac{d a}{d N}=C\left(\Delta K-\Delta K_{t h}\right)^{m_{1}}(1-R)^{m_{2}}
$$

where $a$ is the crack size or length. $N$ is the number of stress cycle. $d a / d N$ is the crack growth per stress cycle. $\Delta K$ is the stress intensity range. $R$ is the stress ratio. $C$ is the crack propaga- 
tion resistance coefficient. $m_{1}$ and $m_{2}$ are the material constants or crack propagation exponents. $\Delta K_{t h}$ is the fracture threshold.

Equation (2) is a $d a / d N-\Delta K-R$ surface equation to express the relationship between the stress intensity range $\Delta K$, stress ratio $R$ and fatigue crack growth rate $d a / d N$ in a three-dimensional coordinate system. The undetermined material constants $C, m_{1}, m_{2}$ and $\Delta K_{\text {th }}$ in Equation (2) can be determined by best fitting from experimental datasets. By means of Equation (2), the $d a / d N-\Delta K-R$ surfaces for both alloys at $25{ }^{\circ} \mathrm{C}$, and $-70{ }^{\circ} \mathrm{C}$ were respectively determined from the experimental datasets in Figs. $4 \mathrm{a}$ and $4 \mathrm{~b}$ (shown in Table 3). The $d a / d N-\Delta K$ curves for both alloys were deduced from the $d a / d N-\Delta K-R$ surface models in Table 3 . The $d a / d N-\Delta K-R$ surfaces (shown in Table 3) are plotted in Figs. $8 \mathrm{a}$ and $8 \mathrm{~b}$, and the $d a / d N-\Delta K$ curves are plotted in Figs. $4 \mathrm{a}$ and $4 \mathrm{~b}$.

From Table 3 and Figs. 4a, 4b, 8a and 8b, it is obvious that: (i) good agreement is achieved between the experimental data and the predicted surface; (ii) the crack propagation resistance coefficients $C$ obtained by best fitting of the modified model are less, but the values of fracture threshold $\Delta K_{t h}$ are greater at $-70^{\circ} \mathrm{C}$ compared to at $25^{\circ} \mathrm{C}$; (iii) the $d a / d N-\Delta K-R$ surfaces are lower at $-70^{\circ} \mathrm{C}$ than at $25^{\circ} \mathrm{C}$; (iv) the crack growth rates for both alloys depicted by the surface model (2) increase with the increasing stress ratio and stress intensity range, respectively; (v) the differences of $d a / d N-\Delta K-R$ surfaces between both temperature environments decrease with the increasing stress ratio and stress intensity range, respectively. Thus, we propose that the surface model (2) has adequately and logically characterized the physical characteristics and the phenomenological quantitative laws of crack growth behaviour. Importantly, the parameters of this model can be determined expediently and easily.

\subsection{Modelling temperature-dependent residual life}

The Willenborg-Chang model based on plastic zone theory has been proved to be successful in 
modelling the load interaction on residual life under random-spectra loading by introducing the effective stress ratio $R_{\text {eff }}$ at crack tip. Therefore, incorporating the Willenborg-Chang model and the $d a / d N-\Delta K-R$ surface model with three-parameter (i.e., Equation (2)), it is possible to predict the crack growth increment for the $i^{\text {th }}$ stress cycle in a block of random-spectrum load history as follows.

If $(\Delta K)_{i} \geq \Delta K_{t h}$, then

$$
\begin{aligned}
& \Delta a_{i}=C\left[(\Delta K)_{i}-\Delta K_{t h}\right]^{m_{1}}\left[1-\left(R_{e f f}\right)_{i}\right]^{m_{2}} \\
& R_{\text {eff }}=1-\frac{\Delta K}{\left(K_{\max }\right)_{\text {eff }}} \\
& \left(K_{\max }\right)_{e f f}=K_{\text {max }}+\frac{\left(K_{\max }\right)_{O L}-\left(K_{\max }\right)_{t h}}{(r-1)\left(K_{\max }\right)_{O L}} K_{\text {max }}-\frac{\left(K_{\max }\right)_{O L}-\left(K_{\max }\right)_{t h}}{(r-1)} \sqrt{1-\frac{\Delta a^{\prime}}{Z_{O L}}} \\
& \left(K_{\max }\right)_{t h}=\frac{\Delta K_{t h}}{1-R} \\
& \mathrm{Z}_{O L}=\frac{1}{2 \pi} \frac{K_{\mathrm{max}}^{2}}{\sigma_{b}^{2}}
\end{aligned}
$$

Otherwise,

$$
\Delta a_{i}=0
$$

where $R_{\text {eff }}$ is the effective stress ratio. $\left(K_{\max }\right)_{\text {eff }}$ is the effective maximum nominal stress intensity. $\left(K_{\max }\right)_{\text {th }}$ is the maximum nominal stress fracture threshold. $\left(K_{\max }\right)_{O L}$ is the overload maximum nominal stress intensity. $Z_{O L}$ is the size of overload plastic zone. $\Delta a^{\prime}$ is the increment of crack growth through the overload plastic zone. $r$ is the overload shut-off ratio and $\sigma_{b}$ is the tensile ultimate strength.

From Equations (3) to (8) and material properties, and actual random-spectra load history, with cycle-by-cycle accumulation damage calculation, all crack growth increments pertaining to each subsequent adjacent stress cycle in actual random-spectra load history can be calculated until final fail- 
ure, and the cumulative number of stress cycle (i.e., residual life or crack growth life) corresponding to each current crack size can be obtained and recorded. Thus the residual life pertinent to final crack size is modelled based on the aforementioned modified damage accumulation rule, incorporating the Willenborg-Chang model and the $d a / d N-\Delta K-R$ surface model. Apparently, the load interaction under actual random-spectra loading is taken into account in residual life prediction through the aforementioned modified damage accumulation rule.

Using the aforementioned modified damage accumulation rule, the residual lives for AAs 2524-T3 and 7050-T7451 were calculated from actual random-spectra load history shown in Fig. 3, the material properties listed in Table 1 , and the $d a / d N-\Delta K-R$ surface models listed in Table 3 . The calculated results are listed in Table 2. The results in Table 2 lead to the following deductions: The maximum relative deviation of residual life predictions for both alloys from experiments is $26.7 \%$, with the acceptable scatter. Thus, it is argued that the modified damage accumulation rule can provide a reasonable prediction for temperature-dependent residual life of metallic alloys.

\section{CONCLUSIONS}

The focus of this paper has been to model the crack propagation in metallic alloys subjected to fatigue loading at low temperature. Fatigue tests were performed on AAs 2524-T3 and 7050-T7451 subjected to constant-amplitude and random-spectra loading histories at $25^{\circ} \mathrm{C}$ and at $-70^{\circ} \mathrm{C}$, respectively. Temperature-dependent residual lives under actual random-spectrum loading were modeled based on a modified accumulation damage rule. The underpinning work contains three features:

(i) Low temperature has a notable and beneficial effect on the crack growth behaviours and residual lives of AAs 2524-T3 and 7050-T7451. The ductile transgranulars nature on fracture surfaces at low temperature decreas crack growth rate, unltimately increasing fatigue life.

(ii) The instantaneous large load variations within actual random-spectra load history enhance the sharply tensile effect to accelerate crack growth. With the increasing reference stress level of random-spectra loading, the load interaction effect enhances, the load-environment interaction weakens, 
and the difference in residual lives between the environments of room and cryogenic temperature decreases.

(iv) A modified accumulation damage rule, accounting for the load interaction, was presented to predict temperature-dependent residual lives of both alloys subjected to actual random-spectrum load history. Good correlation was achieved between the predictions from the modified rule proposed in the paper and actual experiments.

\section{ACKNOWLEDGMENT}

This project was supported by the NSFC (No. 51375033).

\section{REFERENCES}

[1] Carpinteri A, Brighenti R. Fracture and fatigue properties of metallic alloys S275 J2 and A17075 T6 at low temperatures. Journal of Materials Science, 2008; 43: 4780-4788.

[2] Gasquères C, Sarrazin-Baudoux C, Petit J, Dumont D. Fatigue crack propagation in an aluminium alloy at 223K. Scripta Materialia, 2005; 53: 1333-1337.

[3] Burns JT, Gupta VK, Agnew SR, Gangloff RP. Effect of low temperature on fatigue crack formation and microstructure-scale propagation in legacy and modern $\mathrm{Al}-\mathrm{Zn}-\mathrm{Mg}-\mathrm{Cu}$ alloys. International Journal of Fatigue, 2013; 55:268-275.

[4] Goma FAT, Larouche D, Bois-Brochu A, Blais C, Boselli J, Brochu M. Effect of extrusion aspect ratio and test temperatures on fatigue crack growth behavior of a 2099-T83 Al-Li alloy. International Journal of Fatigue, 2014; 59: 244-253.

[5] Jeong DH, Lee SG, Jang WK, Choi JK, Kim YJ and Kim S. Cryogenic S-N fatigue and fatigue crack propagation behaviors of high manganese austenitic steels. Metallurgical and Materials Transactions A, 2013; 44: 4601-4612.

[6] Carpinteri A, Brighenti R, Davoli A, Vantadori S. A micromechanical model for the prediction of the temperature fracture behaviour dependence in metallic alloys. Engineering Fracture Mechan- 
ics, 2008; 75: 3646-3662.

[7] Carpinteri A, Brighenti R, Vantadori S, Viappiani D. Static crack extension prediction in aluminium alloy at low temperature. Engineering Fracture Mechanics, 2008; 75: 510-525.

[8] Yuri T, Ogata T, Saito M, Hirayama Y. Effect of welding structure on high-cycle and low-cycle fatigue properties for MIG welded A5083 aluminum alloy at cryogenic temperature. Cryogenic, 2001; 41: 475-483.

[9] Baek JH, Kim YP, Kim WS, Kho YT. Fracture toughness and fatigue crack growth properties of the base metal and weld metal of a type 304 stainless steel pipeline for LNG transmission. International Journal of Pressure Vessels and Piping, 2001; 78: 351-357.

[10] Jung DH, Kwon JK, Woo NS, Kim YJ, Goto M, Kim S. S-N fatigue and fatigue crack propagation behaviors of X80 steel at room and low temperatures. Metallurgical and Materials Transactions A-Physical Metallurgy and Materials Science, 2014; 45A: 654-662.

[11] Jeong D, Lee S, Seo I, Yoo J, Kim S. Fatigue crack propagation behavior of Fe24Mn steel weld at 298 and $110 \mathrm{~K}$. Metals and Materials International, 2015; 21: 22-30.

[12] Fassina P, Brunella MF, Lazzari L, Re G, Vergani L, Sciuccati A. Effect of hydrogen and low temperature on fatigue crack growth of pipeline steels. Engineering Fracture Mechanics, 2013; 103 : 10-25.

[13] Lü BT, Zheng XL. Predicting fatigue crack growth rates and thresholds at low temperatures. Materials Science and Engineering A, 1991; 148: 179-188.

[14] Vlot A, Massar JMA, Guijt CB, Verhoseven S. Bonded aircraft repairs under variable amplitude fatigue loading and at low temperatures. Fatigue \& Fracture of Engineering Materials \& Structures, 2000; 23: 9-18.

[15] Kim SK, Lee CS, Kim JH, Kim MH, Lee JM. Computational evaluation of resistance of fracture capacity for SUS304L of liquefied natural gas insulation system under cryogenic temperatures using Abaqus user-defined material subroutine. Materials and Design, 2013; 50: 522-532.

[16] Sahu VK, Kumar JKSA, Mohanty JR, Verma BB, Ray PK. Effect of low-temperature overload 
on fatigue crack growth retardation and prediction of post overload fatigue life. Aerospace Science and Technology, 2014; 33: 100-106.

[17] ASTM. Standard test method for measurement of fatigue crack growth rates. ASTM E647-11, West Conshohocken, 2011.

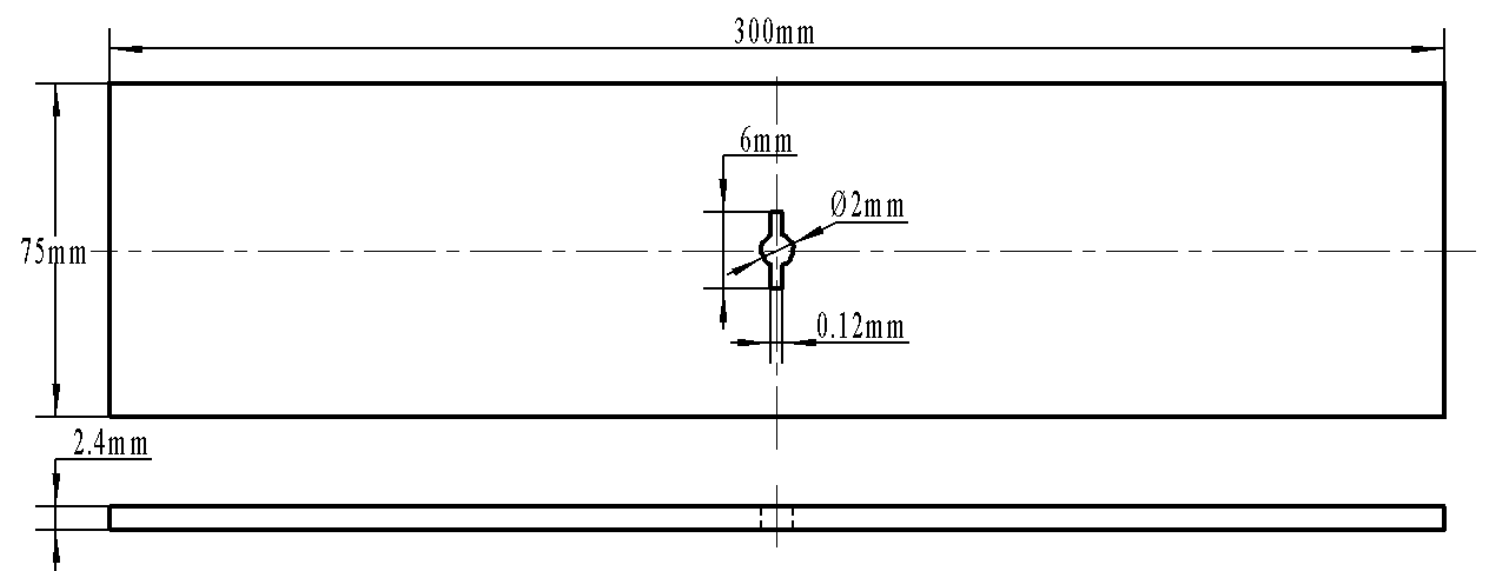

(a) AA 2524-T3

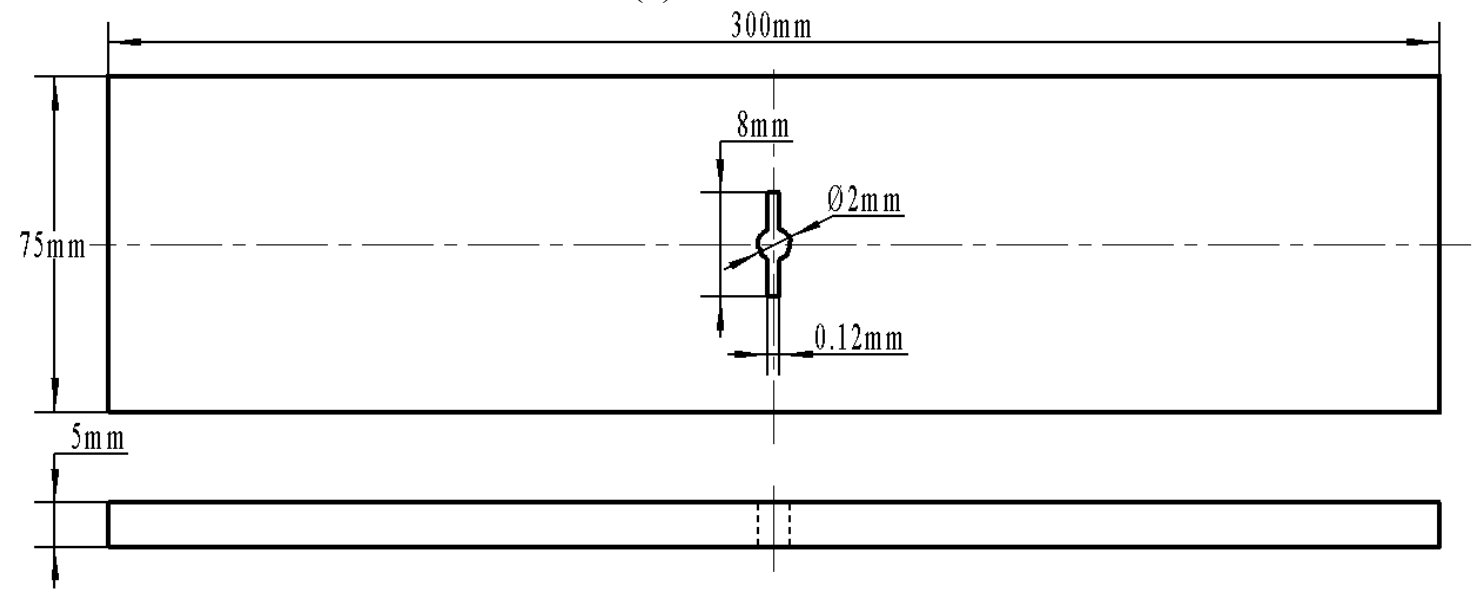

(b) AA 7050-T7451

Fig. 1 CCT specimens
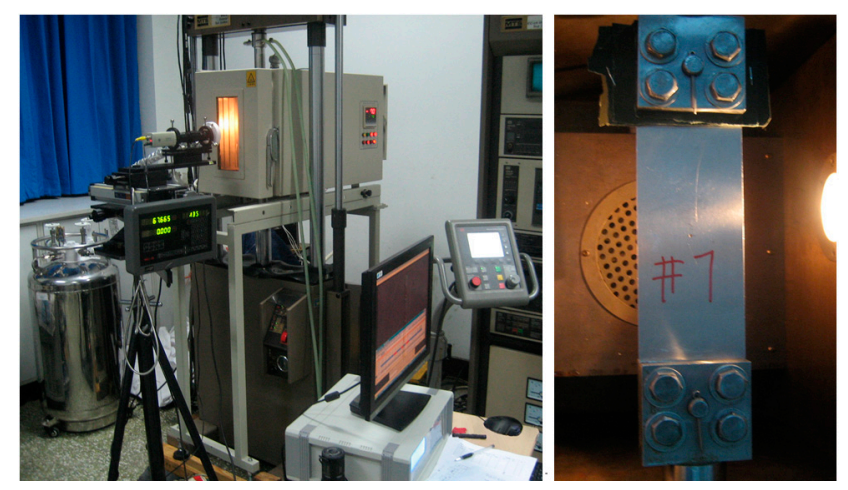

(a) Test setting

(b) AA 2524-T3

Fig. 2 Crack growth measurement 


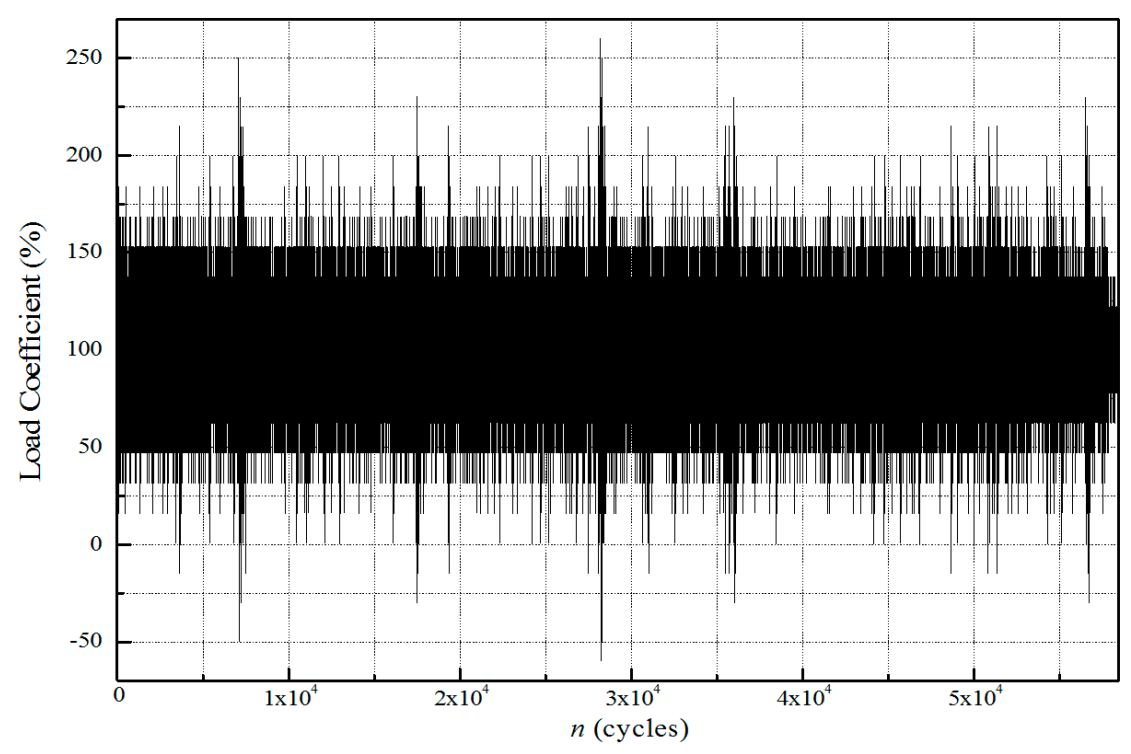

Fig. 3 Actual random-spectra loading history

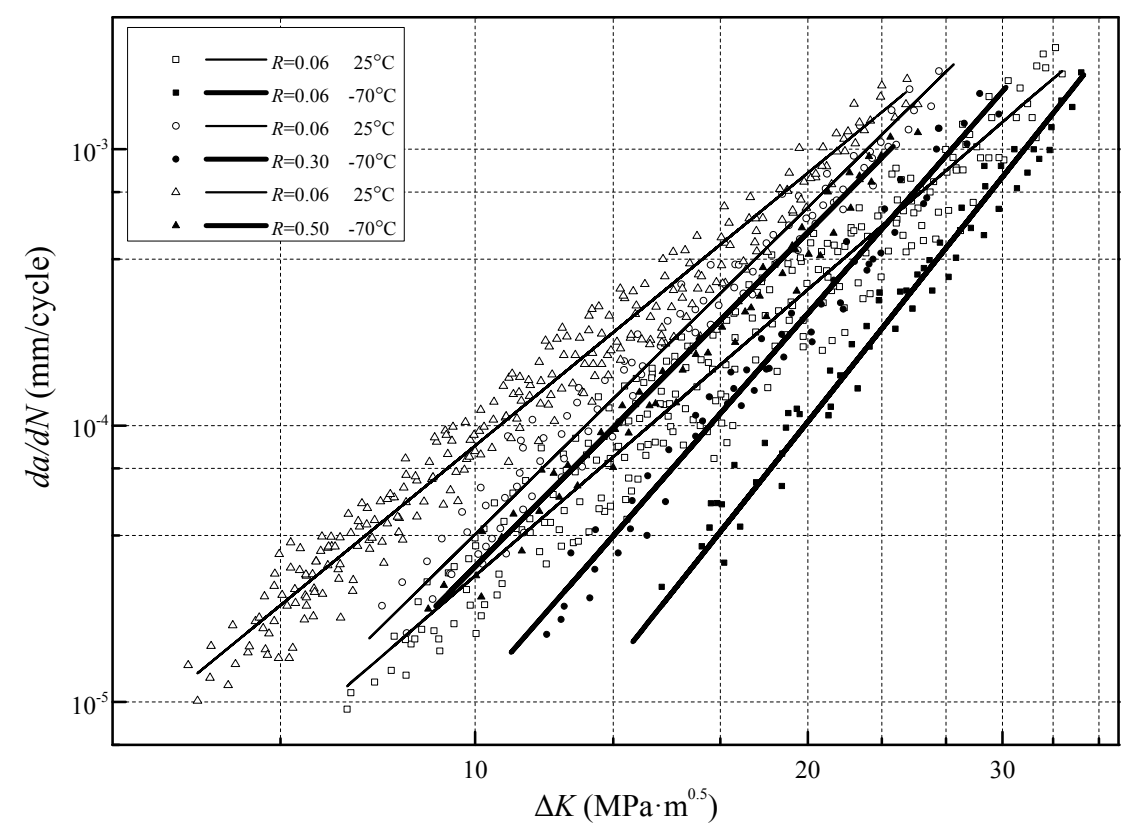

(a) AA 2524-T3 


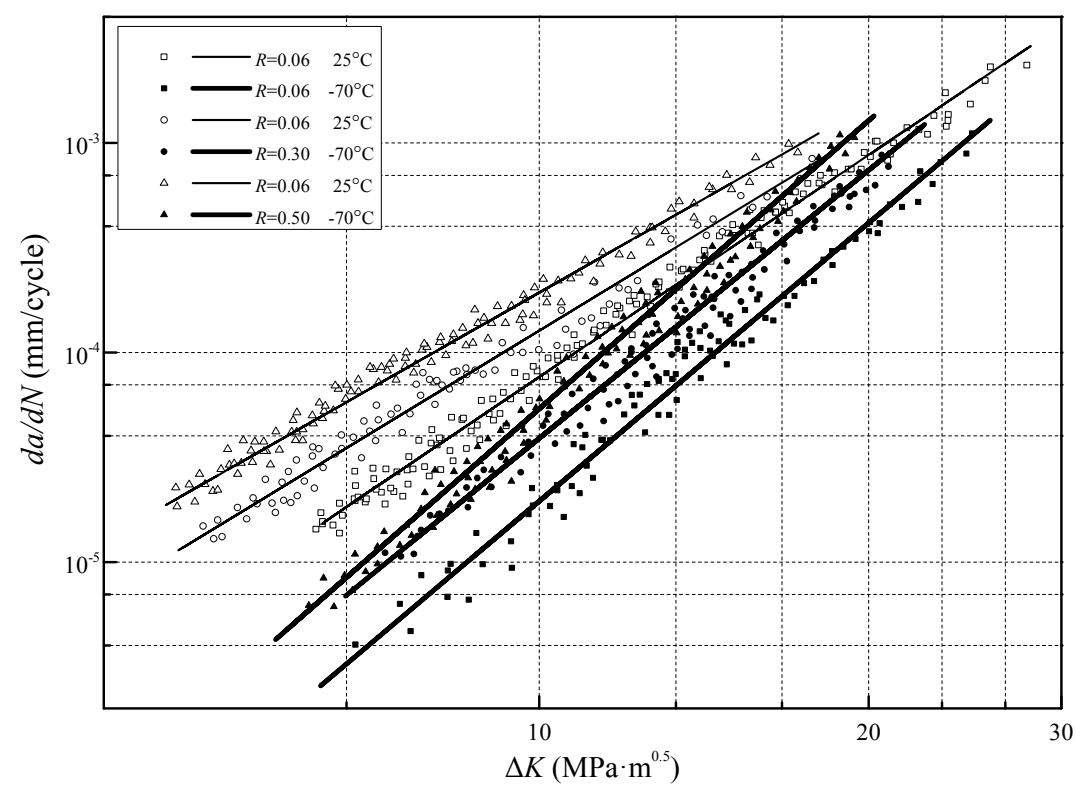

(b) AA 7050-T7451

Fig. 4 Crack growth rate $d a / d N-\Delta K$ curves

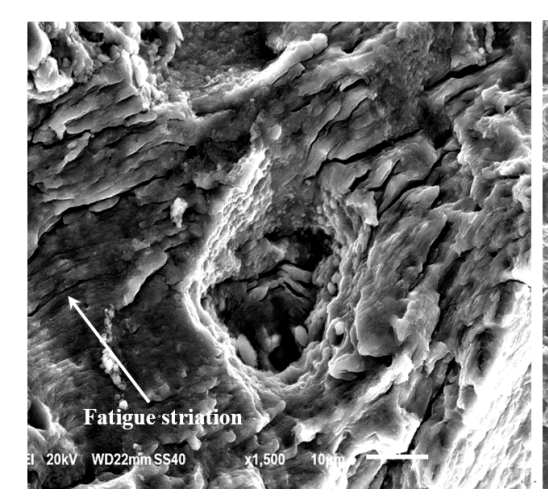

(a) $25^{\circ} \mathrm{C}, N=1.29 \times 10^{5}$ cycles

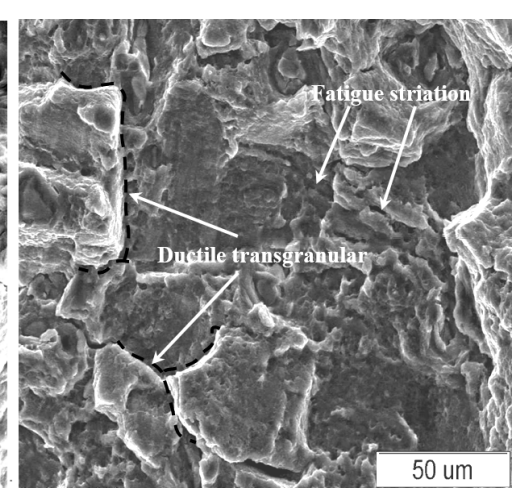

(b) $-70^{\circ} \mathrm{C}, N=2.26 \times 10^{5}$ cycles

Fig. 5 Fractographic pictures for AA 2524-T3 under constant amplitude loading $(R=0.06$,

$$
\left.S_{\max }=182 \mathrm{MPa}\right)
$$

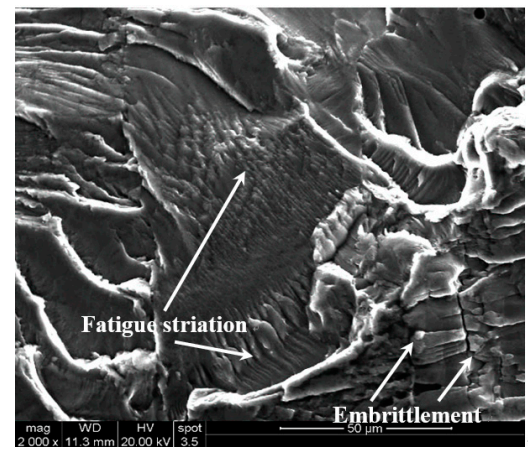

(a) $25^{\circ} \mathrm{C}, N=2.96 \times 10^{5}$ cycles

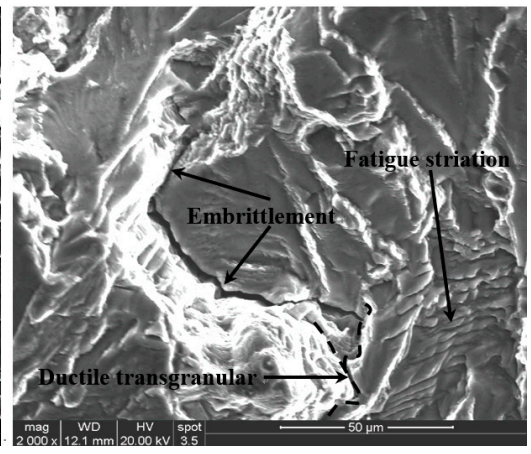

(b) $-70^{\circ} \mathrm{C}, N=2.99 \times 10^{5}$ cycles

Fig. 6 Fractographic pictures for AA 7050-T7451 under constant amplitude loading $(R=0.5$,

$$
\left.S_{\max }=203 \mathrm{MPa}\right)
$$




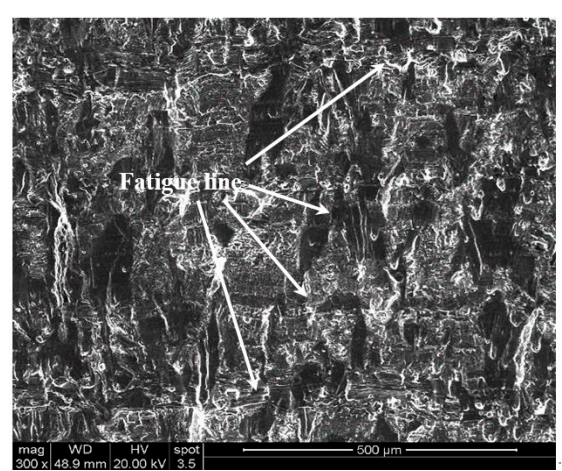

(a) $25^{\circ} \mathrm{C}$, reference stress level of $91 \mathrm{MPa}$

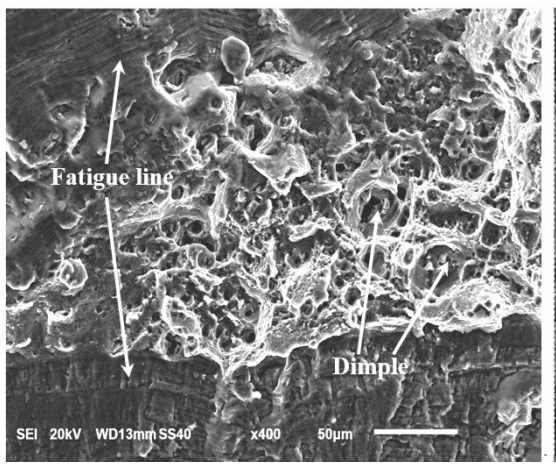

(c) $25^{\circ} \mathrm{C}$, reference stress level of $109 \mathrm{MPa}$

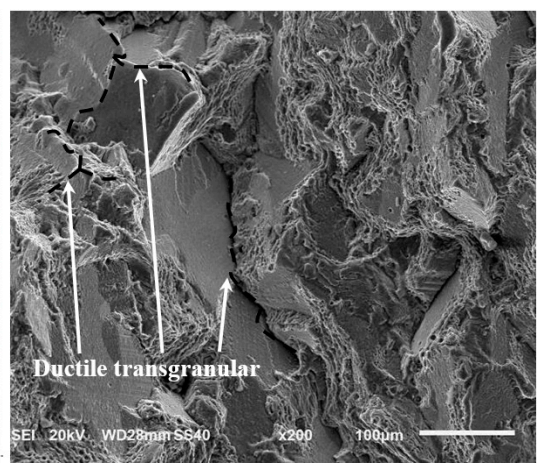

(b) $-70^{\circ} \mathrm{C}$, reference stress level of $91 \mathrm{MPa}$

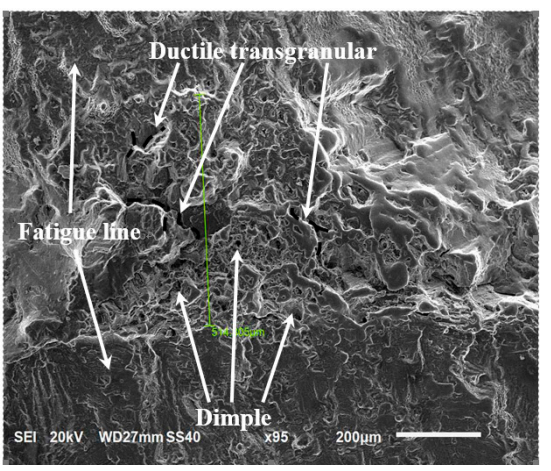

(d) $-70^{\circ} \mathrm{C}$, reference stress level of $109 \mathrm{MPa}$

Fig. 7 Fractographic pictures for AA 2524-T3 under actual random-spectra loading

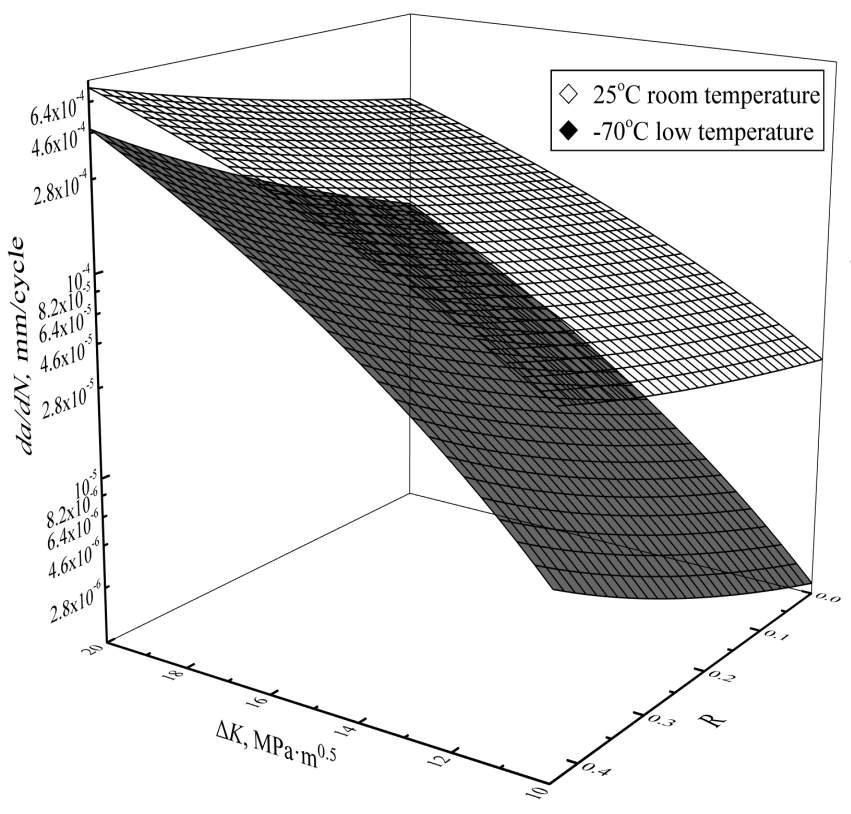

(a) AA 2524-T3

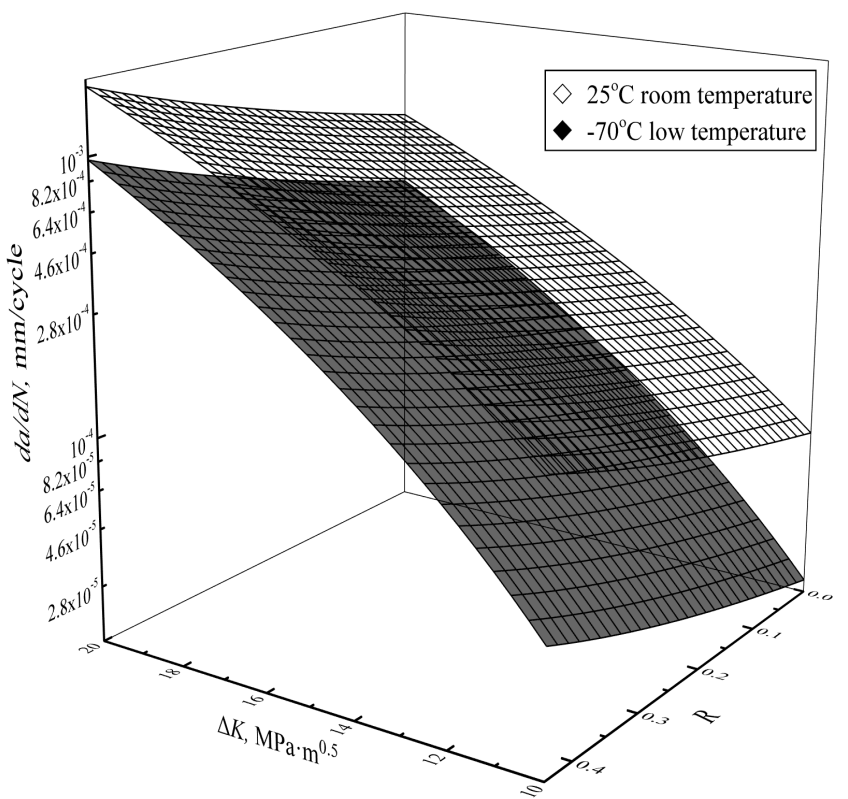

(b) AA 7050-T7451

Fig. 8 Crack growth $d a / d N-\Delta K-R$ surfaces 
Table 1 Material properties of AAs

\begin{tabular}{|c|c|c|}
\hline Aluminum alloy & $\sigma_{b}(\mathrm{MPa})$ & $r$ \\
\hline $2524-\mathrm{T} 3$ & 430 & 2.80 \\
\hline 7050-T7451 & 488 & 2.80 \\
\hline
\end{tabular}

Table 2 Residual lives of AAs under actual random-spectra loading

\begin{tabular}{|c|c|c|c|c|c|c|}
\hline $\begin{array}{l}\text { Aluminum al- } \\
\text { loy }\end{array}$ & Temperature & $\begin{array}{c}\text { Reference } \\
\text { stress level } \\
\text { (MPa) }\end{array}$ & $\begin{array}{l}\text { Experiments } \\
\text { (block) }\end{array}$ & $\begin{array}{l}\text { Mean } \\
\text { (block) }\end{array}$ & $\begin{array}{l}\text { Predictions } \\
\text { (block) }\end{array}$ & $\begin{array}{l}\text { Relative } \\
\text { deviation }\end{array}$ \\
\hline 2524-T3 & $25^{\circ} \mathrm{C}$ & 109 & $4.33,4.43,4.56$ & 4.44 & 3.43 & $22.7 \%$ \\
\hline 2524-T3 & $-70^{\circ} \mathrm{C}$ & 109 & $\begin{array}{c}9.66,10.04, \\
10.07 \\
10.37,11.11\end{array}$ & 10.25 & 7.51 & $26.7 \%$ \\
\hline 2524-T3 & $25^{\circ} \mathrm{C}$ & 91 & $6.98,7.57,7.77$ & 7.44 & 6.19 & $16.8 \%$ \\
\hline 2524-T3 & $-70^{\circ} \mathrm{C}$ & 91 & $\begin{array}{c}18.89,20.58, \\
21.43\end{array}$ & 20.30 & 16.24 & $20.0 \%$ \\
\hline 7050-T7451 & $25^{\circ} \mathrm{C}$ & 75 & $\begin{array}{c}3.70,4.04,4.09 \\
4.15,5.27\end{array}$ & 4.25 & 3.40 & $20.1 \%$ \\
\hline 7050-T7451 & $-70^{\circ} \mathrm{C}$ & 75 & $4.79,5.42,6.62$ & 5.61 & 4.36 & $22.3 \%$ \\
\hline 7050-T7451 & $25^{\circ} \mathrm{C}$ & 68 & $4.61,4.62,5.45$ & 4.90 & 4.39 & $10.4 \%$ \\
\hline $7050-\mathrm{T} 7451$ & $-70^{\circ} \mathrm{C}$ & 68 & $5.01,8.61,9.80$ & 7.81 & 6.29 & $19.5 \%$ \\
\hline
\end{tabular}


Table 3 Crack growth rate $d a / d N-\Delta K-R$ surfaces

\begin{tabular}{|c|c|c|}
\hline Aluminum alloy & Temperature & $d a / d N-\Delta K-R$ surface \\
\hline \multirow{2}{*}{$2524-\mathrm{T} 3$} & $25^{\circ} \mathrm{C}$ & $\frac{d a}{d N}=1.58 \times 10^{-8}(\Delta K-0.52)^{3.29}(1-R)^{-1.71}$ \\
\cline { 2 - 3 } & $-70{ }^{\circ} \mathrm{C}$ & $\frac{d a}{d N}=3.68 \times 10^{-11}(\Delta K-1.24)^{4.94}(1-R)^{-3.28}$ \\
\hline \multirow{2}{*}{$7050-\mathrm{T} 7451$} & $25^{\circ} \mathrm{C}$ & $\frac{d a}{d N}=4.90 \times 10^{-8}(\Delta K-0.21)^{3.21}(1-R)^{-1.54}$ \\
\cline { 2 - 3 } & $-70{ }^{\circ} \mathrm{C}$ & $\frac{d a}{d N}=8.69 \times 10^{-9}(\Delta K-1.92)^{3.69}(1-R)^{-1.63}$ \\
\hline
\end{tabular}

(C) 2016 by the authors; licensee Preprints, Basel, Switzerland. This article is an open access article distributed under the terms and conditions of the Creative Commons by Attribution (CC-BY) license (http://creativecommons.org/licenses/by/4.0/). 